IP Periodica Polytechnica Civil Engineering

\author{
60(1), pp. 3. 2016 \\ DOI: $10.3311 / P P c i .7533$ \\ Creative Commons Attribution (1) \\ RESEARCH ARTICLE
}

\section{A Study on Freeze-Thaw Behavior of Randomly Distributed Fiber-Reinforced Soil}

\author{
A. Sahin Zaimoglu, Yasin Calik, R. Kagan Akbulut, Temel Yetimoglu
}

Received 30-05-2014, revised 21-04-2015, accepted 22-06-2015

\begin{abstract}
The freeze-thaw behavior and compressive strength of soil play a significant role in various engineering applications, such as dams and clay liners in waste containment facilities. The discrete fiber reinforcement technique was proposed in order to increase the soil's freeze-thaw behavior and its compressive strength. In this study, a series of unconfined compression and freeze-thaw tests were carried out in the laboratory in order to investigate the effects of randomly distributed polypropylene fibers with a length of $3 \mathrm{~mm}, 6 \mathrm{~mm}$, and $12 \mathrm{~mm}$ on a soil. Fiber percentage for each length was determined as $0.15 \%, 0.20 \%$, and $0.25 \%$ of the total dry weight of the reinforced soil. The number of freeze-thaw cycles was taken as 1, 3, 5, and 10. The results of the study indicate that an increase of polypropylene fiber length caused an increase in peak stress values. On the other hand, the peak stress of unreinforced and reinforced soil samples generally decreases when the number of freeze-thaw cycles is increased. Samples reinforced with polypropylene fibers usually behave in a more ductile manner than unreinforced samples.
\end{abstract}

\section{Keywords}

Freeze-thaw $\cdot$ Unconfined compression strength $\cdot$ Polypropylene fiber

\section{A. Sahin Zaimoglu}

Department of Civil Engineering, Faculty of Engineering, Ataturk University, Erzurum, Turkey

e-mail: zaimoglu@ atauni.edu.tr

\section{Yasin Calik}

Department of Environment and Urban Planning, Civil Engineer, Erzurum, Turkey

e-mail: yasincalik01@ hotmail.com

\section{R. Kagan Akbulut}

Department of Construction, Technical Vocational School of Higher Education, Ataturk University, Erzurum, Turkey

e-mail: rkakbulut@atauni.edu.tr

\section{Temel Yetimoglu}

Department of Civil Engineering, Faculty of Engineering, Ataturk University, Erzurum, Turkey

e-mail: yetimoglutemel@yahoo.com

\section{Introduction}

The concept of reinforcing soil with natural fibers originated in ancient times. Ancient civilizations used straw and hay to reinforce mud blocks in order to create reinforced building blocks [1]. This study has focused on the effects of discrete reinforcement inclusions on the engineering properties of a fine-grained soil. During the last few decades, randomly distributed fiber reinforcements have attracted increasing attention in geotechnical engineering [2-8]. The primary purpose of reinforcing soil mass is to improve its stability, increase its bearing capacity, and reduce settlement and lateral deformation [9-11]. In comparison with conventional geosynthetics, the advantages of using randomly distributed fibers are as follows: a- Randomly distributed fibers are simply mixed with soil, just like mixing soil with additive materials. b- Randomly distributed fibers limit potential planes of weakness that may develop in the direction parallel to the conventionally oriented reinforcement. c- Fibers have no negative effect on the environment [12].

In regions affected by seasonal climatic changes, soil may be exposed to freeze-thaw cycles several times a year. This, in turn, negatively affects some of the engineering properties of fine-grained soils (water content, ultimate bearing capacity, permeability, etc.). Soil properties, in cold regions where temperature falls below $0^{\circ} \mathrm{C}$ seasonally, must be known before design and construction of structures are built [13]. The freeze-thaw process has more effects on fine-grained soils than on coarsegrained soils [14 15]. Reinforcement elements are placed in the soil in order to reduce the impact of adverse effects of freezethaw phenomenon on some of the engineering properties of fine-grained soils. In comparison with the studies on the compaction and strength characteristics of randomly reinforced cohesive soils [16-30], there are a limited number of studies on the freeze-thaw behaviour of fiber reinforced clays in the literature [14, 29, 34, 35].

In this study, stress-strain and freeze-thaw behaviours of soil reinforced with randomly distributed polypropylene fibers were investigated. A series of unconfined compression and freezethaw tests were carried out in the laboratory. Polypropylene fiber lengths and number of freeze-thaw cycles were chosen as 
parameters in the experiments. The test results for reinforced and unreinforced samples were compared and discussed.

\section{Materials and Methods}

The soil used in this study was supplied from the Cat, Erzurum, Turkey. The result of the particle size analysis of the soil sample is shown in (Fig.11). The x-ray diffraction (XRD) method was used to identify the major minerals in the soil $(<$ No.200 sieve) used in the study. The XRD analyses were performed at the General Directorate of Mineral Research and Exploration (Turkey) on air-dried, solvated with ethylene glycol, soil samples which had been heated to 300 and $500^{\circ} \mathrm{C}$. The XRD diffractogram of soil samples is shown in (Fig. 2). In this study, polypropylene fiber (' $M$ ' type) was used as a reinforcement material. The commercial presentation for the polypropylene fiber and its discrete form used in the experiments are shown in (Fig. 3). The ratio of the fiber (i.e., the content of fiber reinforcement) used in the experiments is expressed in total weight due to the difficulty of determining the volume.

Some of the properties of the soil are given in Table 1 . The specifications of some of the properties provided by the manufacturer of the polypropylene fibers are also given in Table 2

Tab. 1. Some of the properties of the soil used in the experiments

\begin{tabular}{|c|c|}
\hline Properties & Value \\
\hline Specific gravity, $\mathrm{G}_{S}$ & 2.55 \\
\hline Liquid limit ${ }^{1}, \mathrm{w}_{L}(\%)$ & 42 \\
\hline Plastic limit ${ }^{2}, \mathrm{w}_{P}(\%)$ & 21 \\
\hline Plasticity index, $\mathrm{I}_{P}(\%)$ & 21 \\
\hline Optimum water content ${ }^{3}, \mathrm{w}_{\text {opt }}(\%)$ & 19 \\
\hline Maximum dry unit weight ${ }^{3}, \gamma_{d \max }\left(\mathrm{kN} / \mathrm{m}^{3}\right)$ & 17 \\
\hline Unconfined Compression Strength ${ }^{4},(\mathrm{kPa})$ & 167 \\
\hline
\end{tabular}
$\mathrm{w}_{L}$ per BS 1377 (Part 2-1990)
$\mathrm{w}_{P}$ per ASTM D 4318-00 (2000)
Obtained from Standard Proctor Tests (ASTM D 698- 78)
Obtained from the tests on the samples prepared at $\mathrm{w}_{\text {opt }}$ and $\gamma_{d \max }$

4

Tab. 2. Some of the properties of the polypropylene fiber (supplied by the manufacturer)

\begin{tabular}{cc}
\hline Properties & Value \\
\hline Content & $100 \%$ pure polypropylene \\
Appearance & Thin Hair String \\
Length, $(\mathrm{mm})$ & $3-6-12$ \\
\hline Tensile Strength, $\left(\mathrm{N} / \mathrm{mm}^{2}\right)$ & $500-700$ \\
Elongation, (\%) & 25 \\
Colour & Transparent \\
Softening & $150{ }^{0} \mathrm{C}$ \\
Melting & $160{ }^{\circ} \mathrm{C}$ \\
\hline
\end{tabular}

The soil used in the experiments was washed through a ASTM200 sieve $(d=0,074 \mathrm{~mm})$ and dried in an oven at

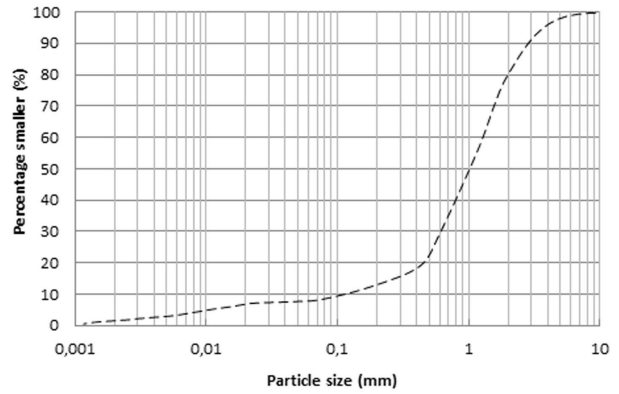

Fig. 1. Particle size distribution curves of soil sample

$105 \pm 5^{\circ} \mathrm{C}$ for 24 hours. Polypropylene fiber lengths were chosen as 3,6, and $12 \mathrm{~mm}$. Fibers were mixed with the dry soil at $0.15,0.20$, and $0.25 \%$ of the total dry weight of the reinforced soil for each fiber length. Because the fibers tend to flocculate, a considerable effort was made to achieve a homogeneous distribution of the fibers in the mixtures. The fiber-soil mixture was compacted in three layers into a cylindrical mould ( $38 \mathrm{~mm}$ in diameter, $76 \mathrm{~mm}$ in height), with optimum water content and dry density. The specimen preparation method was adapted from the standard compaction test method [31]. These cylindrical samples were used in all of the experiments.

Freeze-thaw tests were conducted at a minimum temperature of $-25^{\circ} \mathrm{C}$ and at a maximum temperature of $60^{\circ} \mathrm{C}$ in a programmable freeze-thaw cabinet, with dimensions $110 \mathrm{~cm} \times 55 \mathrm{~cm} \times 55 \mathrm{~cm}$. The programmable freeze-thaw test cabinet is shown in (Fig. 4). These tests were carried out on both reinforced and unreinforced soil samples. Samples, prepared at optimum water content and maximum dry unit volume weight, were wrapped in aluminium foil to avoid changes in their water content [32] (Fig. 4). A thin film layer of Vaseline was spread evenly all over the aluminium foil to prevent the samples from sticking to it [33, 34]. The prepared samples were placed in the programmable freeze-thaw cabinet and tests were performed at $-20^{\circ} \mathrm{C}$ for 6 hours and at $25^{\circ} \mathrm{C}$ for 6 hours. This operation is referred to in this study as Cycle 1 [35]. The number of freeze-thaw cycles was chosen as $1,3,5$, and 10 . The polypropylene fiber percentages and lengths as well as the number of freeze-thaw cycles were chosen in accordance with the literature [35-37]. The samples were not removed from the programmable freeze-thaw cabinet during the experiments.

Unconfined compression tests were conducted on cylindrical specimens prepared at maximum dry unit weight and optimum moisture content. The unconfined compression tests were carried out in accordance with ASTM D 2166 [38]. The reinforced and unreinforced soil samples were loaded in the deformationcontrolled unconfined compression test device at a loading rate of $0.8 \mathrm{~mm} / \mathrm{min}$, in order to observe the stress-strain behaviour. In this test, unconfined compressive strength was taken as the maximum load per unit area or the load per unit area at $15 \%$ axial strain, whichever occurred first during a test [38]. Each test was repeated on three samples to assure the repeatability of the results. The result of each test was taken as the average of three 


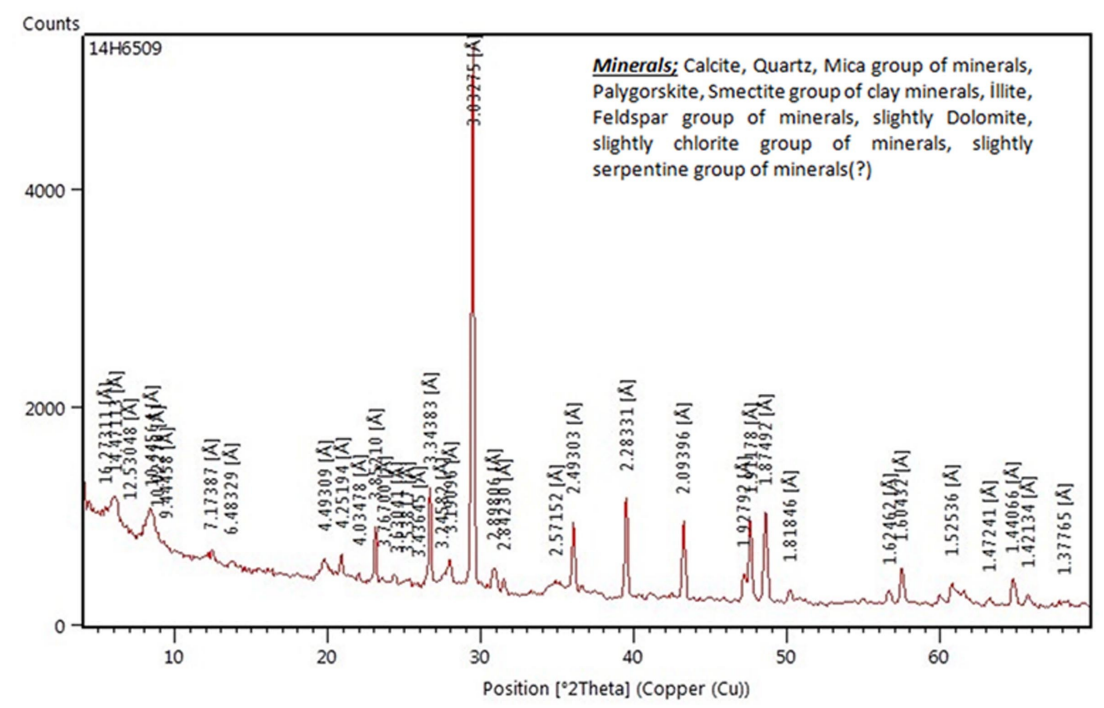

(a)

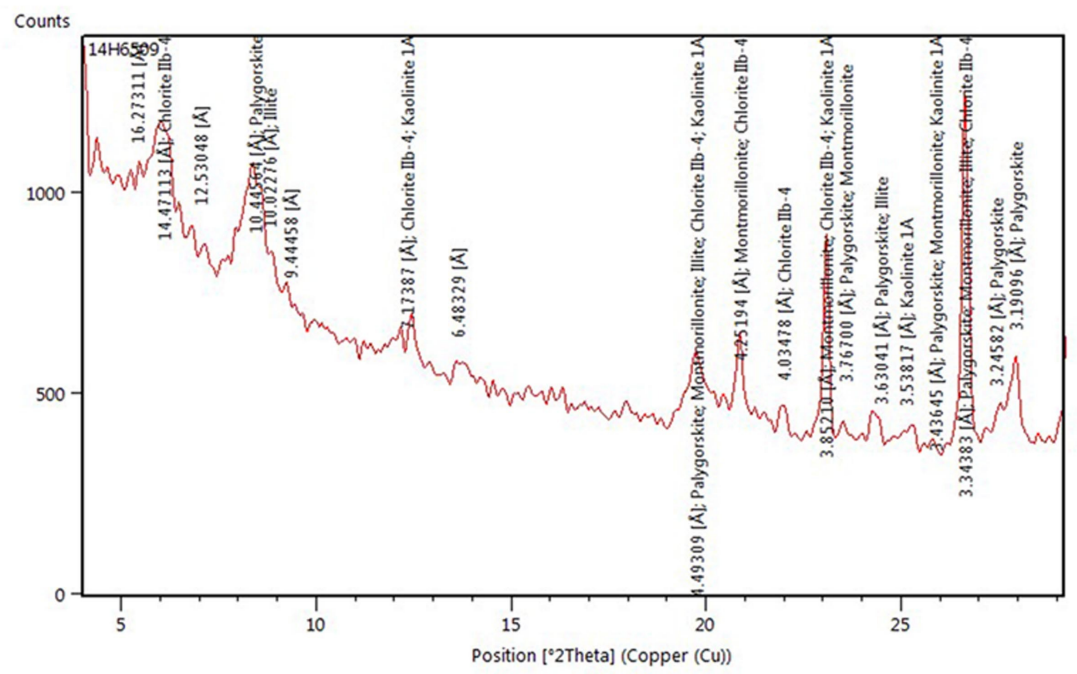

(b)

Fig. 2. A typical XRD analysis result for the soil ( $<$ No. 200 sieve), (a-For the position of $2 \Theta$ between $2^{\circ}$ and $70^{\circ}$; b- For the position of $2 \Theta$ between $2^{\circ}$ and $30^{\circ}$ )

samples and stress-strain curves were used for average values. A scaled image of a typical surface of failure in reinforced and unreinforced samples after the unconfined compression tests is shown in (Fig. 5).

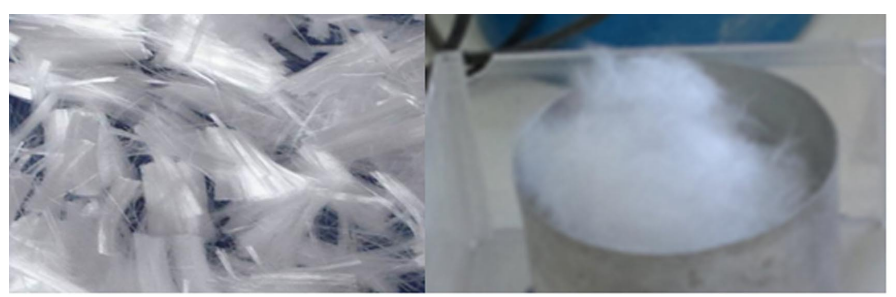

Fig. 3. Polypropylene fiber

\section{Results and Discussions}

The stress-strain curves $(\sigma-\varepsilon)$ obtained from unconfined compression and freeze-thaw tests of samples reinforced by $0.15 \%, 0.20 \%$, and $0.25 \%$ of the polypropylene fibers are shown in Figures 6, 7 and 8, respectively. As can be seen in Fig. 6, the peak stress value of the reinforced soil increases with the in-

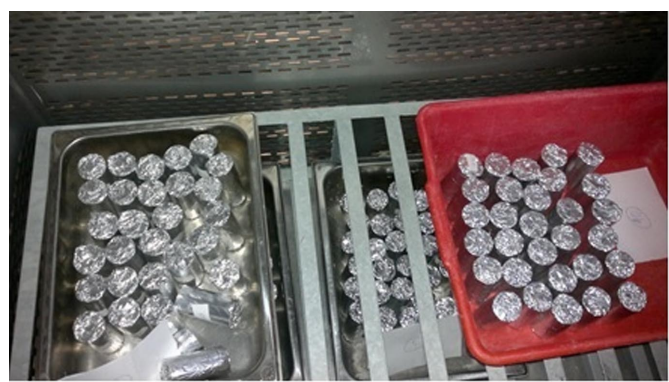

Fig. 4. Fully automatic freeze-thaw cabinet

crease of fiber length. In the situation where there is no freezethaw cycle and $0.15 \%$ polypropylene fiber content, the increase in peak stress values of soil samples reinforced with fibers with a length of $3 \mathrm{~mm}, 6 \mathrm{~mm}$ and $12 \mathrm{~mm}$ is approximately $9 \%, 12 \%$ and $46 \%$, respectively. It can also be seen that unreinforced soil sample mimics a brittle behaviour for all of the freeze-thaw cycles. On the other hand, the reinforced samples exhibit more ductile behaviour. The initial stiffness of reinforced soil appears to be increased by the addition of fiber. 


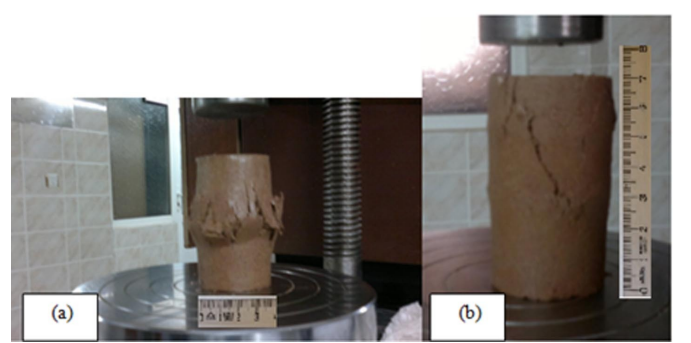

Fig. 5. Typical failure surfaces (a) reinforced - (b) unreinforced

It is believed that this increase might be the result of the mechanical improvement of the load-deformation behaviour, because fibers which are randomly distributed within the soil act as a bridge between soil grains. This phenomenon can be explained by stress transmission from soil to fibers: friction between fiber and soil mobilizes the tensile stresses in fibers when strains in soil mass reach a certain value. Similar results were observed by Singh and Bagra (2013) and Marandi et al. (2008) [7, 8].

As can be seen in (Fig. 6), in general, the peak stress of unreinforced and reinforced soil samples decreases with the increase in the number of freeze-thaw cycles. After freeze-thaw cycles, the highest stress value was observed for the reinforced sample with $12 \mathrm{~mm}$ polypropylene fiber.

(Fig. 7) shows the stress-strain curves of unreinforced and reinforced samples for $0.20 \%$ fiber ratio. The results also showed generally an increase in initial stiffness modulus with the additive fiber. This increase is more considerable for the $12 \mathrm{~mm}$ long fiber reinforced samples. It correlates the interlocking of particles and the bonding between fibers and soil. In other words, the fibers correlate the interlocking of soil particles and these groups of fibers and soil particles behave as a unitary solid matrix, thus may resulted in an increase in soil strength properties [15]. Also, (Fig. 7) clearly shows that the peak stress values of all samples decreased with the increase in the number of freeze-thaw cycles.

The highest unconfined compressive strength in the tests was achieved for the fiber content of $0.25 \%$ (Fig. 8). The reinforced samples with 6 and $12 \mathrm{~mm}$ long fibers exhibit more ductile behaviour than the others. Also, these samples have the highest strength values under the freeze-thaw cycles. The initial stiffness modulus of reinforced samples, especially for $6 \mathrm{~mm}$ and $12 \mathrm{~mm}$ length of fiber is increased more steadily than those of the others.

In summary, the addition of polypropylene fibers has a positive effect on the unconfined compressive strength of the soil. Similar to the findings reported in the literature [2, 4, 11, 29, 35], the test results suggest that the fiber reinforcements can change the brittle behaviour of the clay to a somewhat more ductile (i.e., strain hardening) one. Also, the test results present, in general, a decrease in peak stresses by increasing the number of freeze thaw cycles for both reinforced and unreinforced samples. This decrease may be caused by the capillary holes in the soil formed by polypropylene fibers. Furthermore, the decrease may be at-
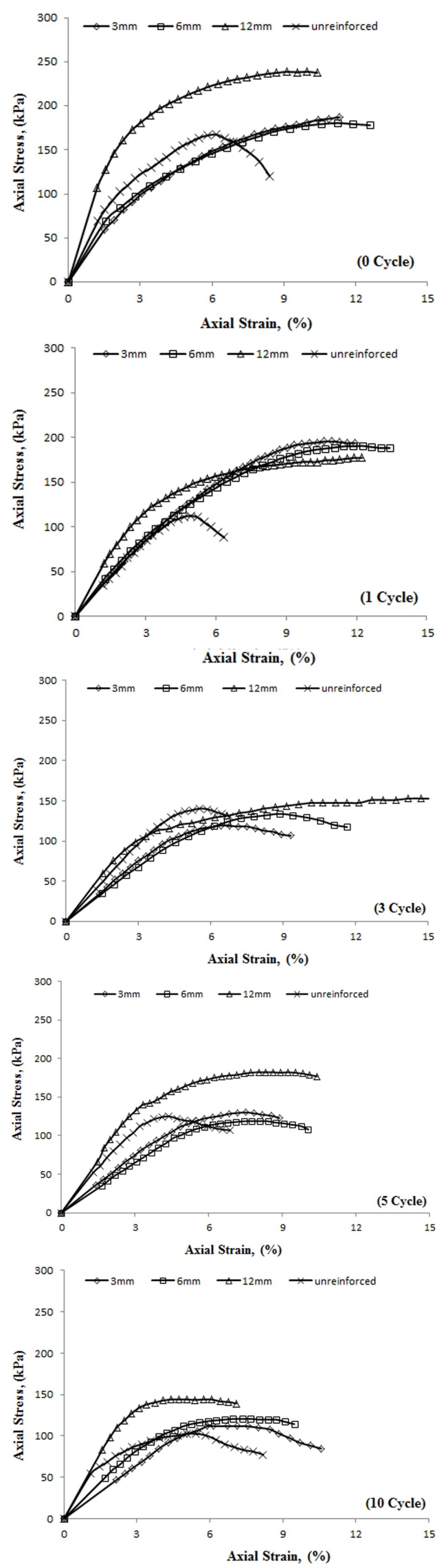

Fig. 6. Stress-strain curves (for $0.15 \%$ polypropylene fiber) 

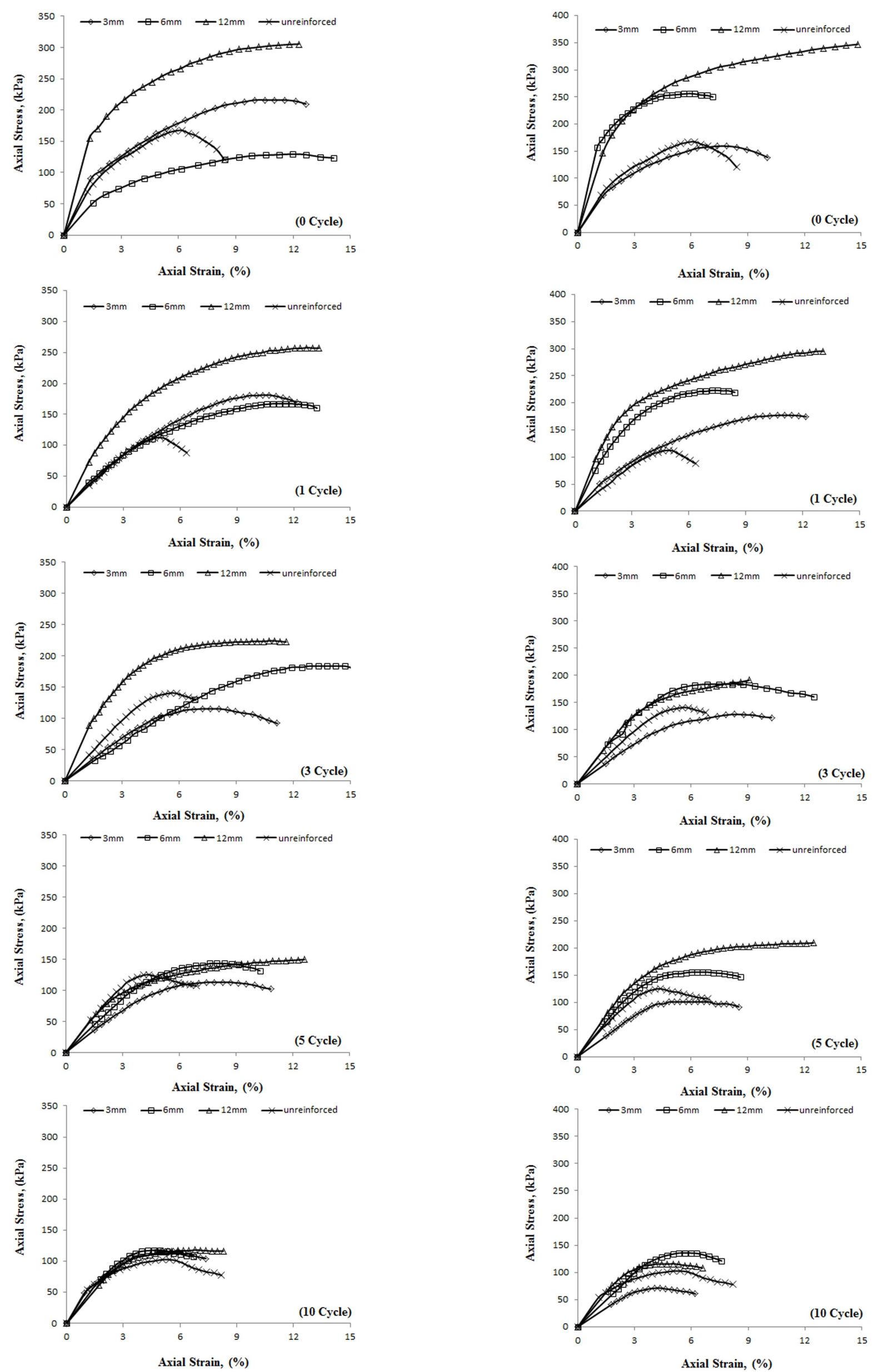

Fig. 7. Stress-strain curves (for $0.20 \%$ polypropylene fiber)

Fig. 8. Stress-strain curves (for $0.25 \%$ polypropylene fiber) 
tributed to the fact that pore water freezes and forms ice lenses in the pore space between the soil grains, then these ice lenses expand in volume and push grains of the soil and act like springs, increasing gaps among soil grains [39].

It should also be pointed out that fiber orientation has a significant effect on the results. Because of the applied sample preparation method, some changed trends, especially for samples with $12 \mathrm{~mm}$ long fibers, could be observed within the experiment series.

\section{Conclusions}

In this study, a series of unconfined compression tests and freeze-thaw tests were carried out in the laboratory. The main subject of the study was to investigate the freeze-thaw behaviour of soil reinforced with randomly distributed fibers in different lengths and rates. The general results from the tests are as follows:

- The unconfined compression strength of soil could be increased significantly by mixing fibers with soil,

- The unconfined compression strength of reinforced soil increased generally with increasing the polypropylene fiber length and content,

- The reinforced soil samples usually exhibited more ductile behaviour than the unreinforced samples,

- Axial stresses decreased when the number of freeze-thaw cycles increased, for both reinforced and unreinforced samples.

In order to make more realistic judgments on the subject, experiments should be continued for further studies with different polypropylene fiber lengths, soil types, number of freezethaw cycles, drainage conditions, time, porosity, void ratio and polypropylene rates. It should also be emphasized that porosity is one of the important index parameters and its development during freeze-thaw cycles is one of the reasons for weakened elastic properties of soil. Further studies to achieve more detailed conclusions should analyse this parameter using the ultrasonic wave propagation test.

\section{Acknowledgement}

This study was supported by the Scientific Research Project of Ataturk University. The authors would like to express their gratitude to Ataturk University for this support.

\section{References}

1 Freilich BJ, Li C, Zornberg JG, Effective Shear Strength of Fiberreinforced Clays, 9th International Conference on Geosynthetics, In: In Proceedings of the 9th International Conference on Geosynthetics; Brazil, 2010, pp. 1997-2000.

2 Yetimoglu T, Salbas $\mathbf{O}$, A study on shear strength of sands reinforced with randomly distributed discrete polypropylene fibers, Geotextiles and Geomembranes, 21(2), (2003), 103-110, DOI 10.1016/S0266-1144(03)000037
3 Tang CS, Shi B, Gao W, Cai Y, Liu J, Study on effect of sand content on strength of polypropylene fiber reinforced clay soil, Chinese Journal of Rock Mechanics and Engineering, 26(Suppl.1), (2007), 2968-2973. (in Chinese).

4 Tang CS, Shi B, Gao W, Influence of polypropylene fiber and cement addition on strength behavior of clay soil and the mechanisms, Journal of Engineering Geology, 15(1), (2007), 108-113. (in Chinese).

5 Ahmad F, Bateni F, Azmi M, Performance evaluation of silty sand reinforced with fibers, Geotextiles and Geomembranes, 28(1), (2010), 93-99, DOI 10.1016/j.geotexmem.2009.09.017

6 Consoli NC, da Fonseca AV, Cruz RC, Silva SR, Voids/cement ratio controlling tensile strength of cement-treated soils, Journal of Geotechnical and Geoenvironmental Engineering, 137(11), (2011), 1126-1131, DOI 10.1061/(ASCE)GT.1943-5606.0000524

7 Singh HP, Bagra M, Strength and stiffness response of Itanagar soil reinforced with jute fiber, International Journal of Innovative Research in Science, Engineering and Technology, 2(9), (2013), 4358-4367.

8 Marandi SM, Bagheripour $\mathbf{M H}$, Rahgozar R, Zare $\mathbf{H}$, Strength and ductility of randomly distributed palm fibers reinforced silty-sand soils, American Journal of Applied Sciences, 5(3), (2008), 209-220, DOI 10.3844/ajassp.2008.209.220

9 Prabakar J, Sridhar RS, Effect of random inclusion of sisal fibre on strength behavior of soil, Construction and Building Materials, 16(2), (2002), 123 131, DOI 10.1016/S0950-0618(02)00008-9

10 Yarbasi N, Kalkan E, Akbulut S, Modification of the geotechnical properties, as influenced by freeze-thaw, of granular soils with waste additives, Cold Regions Science and Technology, 48(1), (2007), 44-54, DOI 10.1016/j.coldregions.2006.09.009

11 Kumar A, Walia BS, Mohan J, Compressive strength of polypropylene fiber reinforced highly compressible clay, Construction and Building Materials, 20(10), (2006), 1063-1068, DOI 10.1016/j.conbuildmat.2005.02.027

12 Li J, Tang C, Wang D, Pei X, Shi B, Effect of discrete fibre reinforcement on soil tensile strength, Journal of Rock Mechanics and Geotechnical Engineering, 6(2), (2014), 133-137, DOI 10.1016/j.jrmge.2014.01.003

13 Cruzda KA, Hohmann M, Freezing effect on strength of clayey soils, Applied Clay Science, 12(1), (1997), 165-187, DOI 10.1016/S01691317(97)00005-7

14 Hazirbaba K, Gullu H, California bearing ratio improvement and freezethaw performance of fine-grained soils treated with geofiber and synthetic fluid, Cold Regions Science and Technology, 63(1), (2010), 50-60, DOI 10.1016/j.coldregions.2010.05.006

15 Hejazi SM, Sheikhzadeh M, Abtahi SM, Zadhoush A, A simple review of soil reinforcement by using natural and synthetic fibers, Construction and Building Materials, 30, (2012), 100-116, DOI 10.1016/j.conbuildmat.2011.11.045

16 Hoare DJ, Laboratory study of granular soils reinforced with randomly oriented discrete fibers, Proceedings of the International Conference on Soil Reinforcement, In: Proceedings of the International Conference on Soil Reinforcement; Paris, France, 1979, pp. 47-52.

17 Wasti Y, Butun MD, Behavior of model footings on sand reinforced with discrete inclusions, Geotextiles and Geomembranes, 14(10), (1996), 575-584, DOI 10.1016/S0266-1144(96)00044-1

18 Santoni RL, Tingle JS, Webster SL, Engineering properties of sand-fiber mixtures for road construction, Journal of Geotechnical and Geoenvironmental Engineering, 127(3), (2001), 258-268, DOI 10.1061/(ASCE)10900241(2001)127:3(258)

19 Kaniraj SR, Havanagi VG, Behavior of cement-stabilized fiber-reinforced fly ash-soil mixtures, Journal of Geotechnical and Geoenvironmental Engineering, 127(7), (2001), 574-584, DOI 10.1061/(ASCE)1090241(2001)127:7(574)

20 Consoli NC, Casagrande MDT, Prietto PDM, Thome A, Plate load test on fiber-reinforced soil, Journal of Geotechnical and Geoenvironmen- 
tal Engineering, 129(10), (2003), 951-955, DOI 10.1061/(ASCE)10900241(2003)129:10(951)

21 Consoli NC, Casagrande MDT, Coop MR, Effect of fiber reinforcement on the isotropic compression behavior of a sand, Journal of Geotechnical and Geoenvironmental Engineering, 131(11), (2005), 1434-1436, DOI 10.1061/(ASCE)1090-0241(2005)131:11(1434)

22 Yetimoglu T, Inanir M, Inanir OE, A study on bearing capacity of randomly distributed fiber-reinforced sand fills overlying soft clay, Geotextiles and Geomembranes, 23(2), (2005), 174-183, DOI 10.1016/j.geotexmem.2004.09.004

23 Babu GLS, Vasudevan AK, Haldar S, Numerical simulation of fiberreinforced sand behavior, Geotextiles and Geomembranes, 26(2), (2008), 181-188, DOI 10.1016/j.geotexmem.2007.06.004

24 Latha GM, Murthy VS, Effects of reinforcement form on the behavior of geosynthetic reinforced sand, Geotextiles and Geomembranes, 25(1), (2007), 23-32, DOI $10.1016 /$ j.geotexmem.2006.09.002

25 Chauhan MS, Mittal S, Mohanty B, Performance evaluation of silty sand subgrade reinforced with fly ash and fibre, Geotextiles and Geomembranes, 26(5), (2008), 429-435, DOI 10.1016/j.geotexmem.2008.02.001

26 Ghazavi M, Lavasan AA, Interference effect of shallow foundations constructed on sand reinforced with geosynthetics, Geotextiles and Geomembranes, 26(5), (2008), 404-415, DOI 10.1016/j.geotexmem.2008.02.003

27 Park S S, Effect of fiber reinforcement and distribution on unconfined compressive strength of fiber-reinforced cemented sand, Geotextiles and $\mathrm{Ge}-$ omembranes, 27, (2008), 162-166, DOI 10.1016/j.geotexmem.2008.09.001

28 Zhou HB, Wen XJ, Model studies on geogrid- or geocell-reinforced sand cushion on soft soil, Geotextiles and Geomembranes, 26(3), (2008), 231238, DOI $10.1016 /$ j.geotexmem.2007.10.002

29 Zaimoglu AS, Freezing-thawing behavior of fine-grained soils reinforced with polypropylene fibers, Cold Regions Science and Technology, 60, (2010), 63-65, DOI 10.1016/j.coldregions.2009.07.001

30 Zaimoglu AS, Hattatoglu F, Akbulut RK, Yetimoglu T, Freeze-thaw behavior of fine grained soils subjected to surcharge loads, 3rd International Conference on New Developments in Soil Mechanics and Geotechnical Engineering, In: 3rd International Conference on New Developments in Soil Mechanics and Geotechnical Engineering; Nicosia, North Cyprus, 2012, pp. 495-500.

31 ASTM D-698. Standard test method for laboratory compaction characteristics of soil using standard effort, American Society for Testing and Materials, 1991.

32 Kvaerno HS, Oygarden L, The influence of freeze-thaw cycles and soil moisture on aggregate stability of three soils in Norway, Catena, 67, (2006), 175-182, DOI $10.1016 /$ j.catena.2006.03.011

33 Qi J, Ma W, Song C, Influence of freeze-thaw on engineering properties of silty soil, Cold Regions Science and Technology, 53, (2008), 397-404.

34 Gullu $\mathbf{H}$, Hazirbaba K, Unconfined compressive strength and post-freezethaw behavior of fine-grained soils treated with geofiber and synthetic fluid, Cold Regions Science and Technology, 62, (2010), 142-150, DOI 10.1016/j.coldregions.2010.04.001

35 Ghazavi M, Roustaie M, The influence of freeze-thaw cycles on the unconfined compressive strength of fiber-reinforced clay, Cold Regions Science and Technology, 61, (2010), 125-131.

36 Liu J, Wang T, Tian Y, Experimental study of the dynamic properties of cement- and lime- modified clay soils subjected to freeze-thaw cycles, Cold Regions Science and Technology, 61, (2010), 29-33, DOI 10.1016/j.coldregions.2010.01.002

37 Hazirbaba K, Zhang Y, Hulsey JL, Evaluation of temperature and freeze-thaw effects on excess pore pressure generation of fine-grained soils, Soil Dynamics and Earthquake Engineering, 31(3), (2011), 372-384, DOI 10.1016/j.soildyn.2010.09.006
38 ASTM D 2166. Standard test method for unconfined compressive strength of cohesive soil, American Society for Testing and Materials, 1991.

39 Tunc A, Geotechnic and Its Applications on Road Engineering, Atlas Publisher; Istanbul, Turkey, 2002. in Turkish. 